\title{
Lymphomatous Involvement of Non- Cutaneous Extranodal Site
}

National Cancer Institute

\section{Source}

National Cancer Institute. Lymphomatous Involvement of Non-Cutaneous Extranodal

Site. NCI Thesaurus. Code C114840.

A pathologic and/or clinical finding indicating the spread of a lymphomatous process to an anatomic site other than lymph nodes and skin. 